\title{
HUBUNGAN MASYARAKAT JAWA TONDANO DENGAN MINAHASA
}

\section{Java Tondano Relation with Minahasa Community}

\author{
Wardiah Hamid
}

\author{
Balai Penelitian dan Pengembangan Agama Makassar \\ J1. A.P Pettarani No 72 Makassar \\ E-mail: wardiahlitbang@yahoo.co.id
}

\begin{abstract}
Abstrak
Kiyai Mojo dan para pengikutnya, sebagai pendiri awal kampung Jawa Tondano, sebelumnya mereka tergabung dalam Perang Diponegoro yang terjadi pada tahun 1825-1830. Perang ini amat merugikan dan menyulitkan kompeni Belanda, sehingga mereka menggunakan kebijakan mengasingkan para pejuang yang tertangkap ke berbagai daerah. Salah satu wilayah pengasingan adalah daerah Tondano Minahasa. Para mantan pejuang ini kemudian membentuk komunitas Islam Jawa Tondano di Minahasa. Persoalannya, bagaimana hubungan antar masyarakat Jawa Tondano dan masyarakat Minahasa? Penelitian ini dapat mengungkap secara spesifik sejarah hubungan antara masyarakat Kampung Jawa Tondano yang Islam dan masyarakat Minahasa yang Kristen, beserta perubahan sosialnya. Penelitian yang menggunakan metode kualitatif dengan pendekatan sejarah dan sosiologi ini telah menunjukan bahwa sejak awal hubungan antara Islam kampung Jawa Tondano dan masyarakat Kristen Minahasa telah harmonis melalui perkawinan, kekerabatan, dan menjadikan lahan mata pencarian sawah sebagai ruang sosial bersama perjumpaan antara dua komunitas yang berbeda itu.
\end{abstract}

Kata kunci: Kiyai Mojo, hubungan masyarakat, Kampung Jawa Tondano

\begin{abstract}
Java Tondano community in Minahasa was established by Kyai Mojo and his followers during their exile by Dutch due to their alliance with Diponegoro in a war to fight against Dutch colonization inl825 -1830. The case of research was inter relation between muslim community of Java Tondano and their surrounding Christian community of Minahasa. This study aims to reveal the specifichi story of their relation as well as its social changes. Qualitative research with sociological and historical approach reveal that the relation between two communities is harmonious established through marriage, kinship, ana shared social spaceof encounter through shared live lihood of cultivating paddy land.
\end{abstract}

Keywords: Kiyai Mojo, the relationship between people, Tondano Javanese village

\section{PENDAHULUAN}

$\mathrm{P}$ erang Diponegoro tercatat dalam sejarah sebagai perang yang menguras habis kas

Belanda. Setidaknya ada tiga kebijakan yang dilahirkan saat dan pasca peperangan ini, yaitu (a) kebijakan pengasingan bagi para pemberontak yang melawan Belanda; (b) pemberlakuan sistem culturstelsel dalam pertanian; dan (c) pemberlakuan pas jalan bagi penduduk jajahan, (Suharnono Pranoto W, 2010:78). Dua hal terakhir menyebabkan banyaknya pemberontakan terjadi di beberapa daerah pedalaman Jawa. Sementara kebijakan pengasingan telah menyebabkan banyaknya para pejuang di pedalaman Jawa Tengah dibuang ke wilayah-wilayah yang tidak dikenal sebelumnya.

Pada tahun 1829, sekitar 60 orang pejuang Jawa yang tangkap oleh kompeni Belanda dikirim ke seberang lautan menuju ke tempat pengasingan di ujung utara pulau Sulawesi. Saat itu, orang-orang buangan tersebut bukan hanya berstatus sebagai orang Jawa pejuang, tetapi juga seorang Muslim. 
Mereka pada akhirnya membangun perkampungan Muslim di tengah-tengah daerah Kristen Minahasa (Yayasan Kiyai Mojo, 1979: 20). Daerah ini kemudian mengalami suatu perubahan cepat. Pada awalnya, orang buangan itu kawin mawin dengan wanita pribumi non muslim, membentuk keluarga, dan akhirnya membangun perkampungan.

Sayangnya, pada perkembangan selanjutnya pemukiman Muslim di Kampung Jawa Tondano (Jaton) dianggap sebagai masalah bagi eksistensi pemeluk agama Kristen, karena mereka hidup di tengah-tengah pemeluk mayoritas. Ada anggapan bahwa kehadiran mereka itu bisa menyebabkan lemahnya keimanan umat Kristen. Sementara masyarakat Muslim Kampung Jawa Tondano tetap memegang nilai-nilai Islam sebagai salah satu benteng yang kokoh keimanan mereka. Pembauran ini tidak terlepas dari latar belakang datangnya agama Islam di Tondano, untuk selanjutnya perkembangan agama Islam seiring dinamika budaya di Sulawesi Utara khususnya masyarakat Minahasa. Kedua komunitas ini menjadi sesuatu yang menarik untuk dikaji dengan menyamakan persepsi dan kesadaran pada kedua komunitas ini, yaitu ikatan kekeluargaan di masa lampau yang harmonis diharapkan tidak ada riak-riak konflik di kemudian hari.

Persoalannya, bagaimana sejarah hubungan antar masyarakat Jawa Tondano dan Minahasa dalam konteks lokal? Sedangkan tujuannya adalah untuk mengetahui hubungan antar masyarakat kampung Jawa Tondano dan masyarakat Minahasa, dan mengurai sejarah komunitas Islam Jawa Tondano, serta perjumpaan mereka dengan komunitas Kristen Minahasa. Penelitian ini dapat bermanfaat bagi pemerhati sejarah di Sulawesi Utara dan secara terkhusus bagi generasi keturunan Jaton di manapun mereka berada. Bagi praktisi maupun instansi pemerintah, setidaknya temuan ini dapat memberikan pertimbangan dalam mengeluarkan kebijakan khususnya kerukunan umat beragama di kampung Jawa Tondano Minahasa untuk berada dalam kondisi bingkai kerukunan umat beragama yang harmonis.

Kearifan dan kerukunan harmonis (integrasi sosial bagain dari perubahan sosial) seturut dengan teori perubahan sosial Emile Durkheim and Ferdinand Tonies berpendapat bahwa perubahan karena evolusi memengaruhi cara pengorganisasian masyarakat terutama yang berhubungan dengan kerja. Mengenai perubahan sosial, Arnoldy Toynbee mengemukakan teorinya yang terkenal dengan Challengge and respon atau tantangan dan tanggapan dia mengamati bahwa suatu masyarakat yang mampu merespon menyesuaikan diri dengan tantagan-tantagan yang ada, maka masyarakat itu akan bertahan dan berkembang. Sebaliknya, jika tidak mampu merespon tantangan yang ada maka akan mengalami kemunduran akhirnya punah (Robert, 2003:51). Selanjutnya menurut Le play memulai analisis keluarga sebagai unit sosial fundamental dari masyarakat. Organisasi keluarga ditentukan oleh cara-cara mempertahankan kehidupannya yaitu cara mereka bermata pencaharian. Hal tersebut sangat tergantung pada lingkungan timbal-balik antara faktor-faktor tempat, pekerjaan dan manusia (hhtp ikhsanhanto. blog spot.com/ diunduh tanggal 24 Agustus 2014). Teori ini mengungkap adanya korelasi antara aneka ragam karakteristik kehidupan masyarakat kampung Jawa Tondano dengan masyarakat Minahasa ditentukan oleh keluarga dengan tali kekerabatan sebagai jembatan hubungan emosional. Dan wadah pertanian sebagai mata pencaharian kedua komunitas ini.

\section{Metode Penelitian}

Sesuai permasalahan yang diajukan serta tujuan yang ingin dicapai dalam penelitian ini, maka metode penelitian yaitu metode kualitatif dengan menggunanakan pendekatan sejarah dan pendekatan sosiologis untuk mengungkap dan menganalisa rekonstruksi fakta sejarah. Metode sejarah adalah proses menguji dan menganalisa secara kritis rekaman dan peninggalan masa lampau (Louis Gottsschalk, 2008: 12). Melalui pengungkapan fakta sejarah masa lalu dalam merekonstruksi kejadian masa lampau, maka peneliti menggunakan interprestasi sejarah. Interpretasi sejarah yang dipahami sebagai menafsirkan, memahami dan mengerti, cukup menjelaskan adanya subjektivisme dan relativisme dalam penjelasan sejarah.(Kuntowijoyo, 2008: 44). Selain metode sejarah, pendekatan sosiologi pun dipergunakan dalam memahami kondisi sosial kemasyarakatan di kampung Jawa Tondano. 
Secara sederhana sosiologi dapat diartikan sebagai ilmu yang menggambarkan keadaan masyarakat lengkap dengan struktur lapisan dan berbagai gejala sosial lainnya yang saling berhubungan (Nata, 2000: 4). Jenis data mencakup data kualitatif yang dijabarkan dalam kalimat pernyataan dan penjelasan. Sumber data primer langsung ditemui di lokasi penelitian. Sumber data sekunder diperoleh dari literatur tulisan media cetak dan elektronik. Sumber data dari penelitian ini berupa informasi penelitian dari tokoh masyarakat kampung dan pemerhati sejarah kampung Jawa Tondano.

Selain itu, dilakukan juga pengamatan terhadap aspek-aspek terkait obyek penelitian. Hal ini dilakukan dengan cara observasi lapangan dengan pengamatan langsung yang dibantu oleh alat perekam dan pencatatan. Pengamatan secara intensif dengan menggunakan pendekatan sosiologis terhadap masyarakat Kampung Jawa Tondano dengan cermat dan tanggap. Seluruh prosesnya diusahakan terfokus pada pendekatan sosiologis dengan masyarakat kampung Jawa Tondano. Kejelian peneliti mengungkap fenomena sosial menjadi nilai tambah data yang diperoleh.

Analisis data dilakukan dengan cara dilakukan interpretasi terhadap data. Data dikumpulkan kemudian diseleksi dan diorganisasi sedemikian rupa lalu dilakukan suatu penafsiran dalam tingkat kepentingan pada nilai-nilai yang terkandung dari data tersebut. Setelah itu, dilakukan interpretasi terhadap fakta-fakta yang diperoleh atas dasar pengetahuan ide-ide, konsep-konsep yang ada dalam kebudayaan masyarakat bersangkutan (Geertz, 1992: 15) Data yang ada diseleksi sedemikian cermat, sehingga dapat dimaknai dan ditafsirkan sesuai kondisi masyarakat kampung Jawa Tondano.

\section{PEMBAHASAN}

\section{Sejarah Masyarakat Muslim Kampung Jawa Tondano}

Berbagai kajian sejarah tentang Indonesia, menunjukkan sejumlah agama secara bergantian mewarnai kehidupan masyarakat di Nusantara, mulai dari animisme sampai pengaruh agama Hindu, Islam, dan Kristen. Hal ini dimungkinkan karena secara geografis Indonesia memiliki lautan lebih luas dibandingkan luas daratan, sehingga memudahkan untuk diakses. Terlebih masyarakat yang tinggal di wilayah pesisir sangat lebih mudah terakses oleh dunia luar dan kebudayaan asing dibandingkan mereka yang tinggal di pedalaman dan pegunungan (Shihab, 1998: 15). Wilayah pedalaman Minahasa merupakan daerah yang sangatlah sulit untuk mendapat pengaruh dari luar. Berada di atas pedalaman memungkinkan daerah ini memiliki budaya khas tersendiri yang terbentuk secara alamiah tanpa terasimilasi dengan kultur budaya lain.

Salah satu wilayah sebagaimana diterangkan di atas, adalah pengaruh dan keberadaan Islam ketika masuk ke Tondano, sebagai dampak tidak langsung dari kebijakan pengasingan yang dilakukan Belanda terhadap pemberontak Jawa. Walaupun ada pendapat bahwa kerangka Islamisasi secara umum di Sulawesi Utara diduga berlangsung dalam kurun waktu yang berbeda dan sarana jalur yang berbeda ketika ia memasuki wilayah Tondano.

Perang Jawa (1825-1830) merupakan nama lain dari pemberontakan di seluruh Jawa Tengah dan Jawa Timur yang berpusat di kawasan Yogyakarta. Saat itu, 15 dari 29 orang pangeran bergabung dengan Diponegoro. Demikian juga 41 dari 80 bupati (pejabat senior istana) ikut bergabung. Tidak hanya itu, komunitas agama yang bergabung dengan Dipenegoro adalah Kiyai Mojo, dan beliaulah yang menjadi pimpinan spiritual pemberontakan. Sejak tahun 1827, Pangeran Diponegoro dan sejumlah pasukannya sering dikejar dan akhirnya terjepit. Di sinilah banyak korban di kedua belah pihak pada tahun 1829. Di tahun itu, Kiyai Mojo, paman Diponegoro Pangeran Mangkubumi, dan panglima Sentot ketiganya menyerah. Akhirnya di bulan Maret 1830, Pangeran Diponegoro melakukan perundingan di Magelang. Sayangnya, pihak Belanda tetap mengasingkan beliau ke Manado kemudian ke Makassar (Ensiklopedia Jaton, 2009)

Pemerintah Belanda memutuskan untuk mengasingkan Kiyai Mojo beserta sejumlah pengikutnya ke ujung utara pulau Sulawesi. Menurut beberapa informasi lisan dari tokoh Kampung Jawa Tondano bahwa Kiyai Mojo tiba di Minahasa pada tahun 1829. Kiyai Mojo dan rombongannya mulamula ditempatkan di Minahasa Utara bagian timur tepatnya desa Kema. Dari sini mereka dipindahkan ke Tasik Oki atau Tanjung Merah lebih utara dari 
tempat semula. Akhirnya, mereka dipindahkan ke daerah dekat Tondano (Minahasa Tengah), yaitu daerah pertahanan Tonsea lama dan Tondano atau daerah yang didiami sub suku Tonsea dan Tondano. Tempat itu berada paling ujung Selatan negeri Tonsea Lama dan paling Utara ujung negeri Tondano sekarang. Masarang ke bukit pegunungan Lembean kecuali negeri Tonsea Lama. Bertempat di Bangsal tadi itulah sekarang Kiyai Mojo dan rombongan tinggal, sedangkan Kontroler sendiri bertempat tinggal di Loji Tondano, kampung Liningaan sekarang. Belanda memilih daerah ini bagi orangorang buangannya, dengan asumsi bahwa mereka akan mengalami kepunahan (Balai Arkeologi Manado 1998: 11). Perhitungan Belanda meleset, karena orang-orang Tonsea dan Tondano menerima mereka sebagai kawan yang sama-sama membenci Belanda. Pengambilan jodoh gadis-gadis Minahasa dan Tonsea oleh orang Jawa Islam itu menjadi bukti otentik. Mereka akhirnya membentuk keluarga dengan menikahi wanita dari daerah Minahasa. Hal ini disebabkan oleh isteri-isteri mereka tidak dibawa serta dalam pengasingan

Keadaan seperti ini telah membuat Kiyai Mojo dan para pengikutnya sadar bahwa pedalaman alam Minahasa begitu keras untuk bertahan hidup. Upaya untuk menaldukkan alam setempat perlu pemikiran strategi yang matang. Rancangan maket perkampungan di daerah pengasingan pun kemudian dibangun. Awalnya, pembangunan areal pertanian dari daerah rawa, sehingga menjadi daerah pertanian yang subur dan dapat menghasilkan panen yang melimpah. Proses inilah yang merupakan langkah awal simpati penduduk Tondano dan Tonsea kepada kaum pendatang. Realisasi rasa simpati itu dengan diterimanya peminangan Kiyai Tumenggung Pajang dan Kiyai Gazali Mojo terhadap putri kepala walak Tonsea. Dalam peristiwa ini dimulai pengislaman kedua mempelai pengantin putri, menyusul perkawinan lainnya dengan mengislamkan penduduk pribumi (Wawancara Ahmad Tumenggung Zees).

Dengan demikian terbentuklah keluarga yang suaminya merupakan orang Jawa dan isteri orang Tondano dan Tonsea lama dan anak-anak mereka dikenal turunan Jawa Tondano Tonsea. Akhirnya, mereka kemudian dikenal sebagai Jawa Tondano, karena sebagian besar pengikut Kiyai Mojo kawin dengan wanita Tondano. Melalui cara inilah, integrasi sosial antara orang Jawa dengan orang Tondano dan Tonsea melalui sarana perkawinan terjadi secara lintas generasi.

\section{Perjumpaan Muslim-Kristen Minahasa.}

Beberapa ketentuan diberikan oleh Residen Belanda di Minahasa kepada Kiyai Mojo dan para pengikutnya yaitu hak dan kewajiban sama dengan penduduk Minahasa, yaitu tunduk pada Reglemen (hukum) Kepemerintahan, dengan syarat tidak lagi melakukan pemberontakkan dengan cara memengaruhi penduduk pribumi untuk membenci Belanda. Kiyai Mojo diberikan kebebasan untuk menjalankan agamanya, diperbolehkan kawin mawin dengan penduduk pribumi, tunjangan hidup sebanyak empat ringgit perbulannya diberikan kepada Kiyai Mojo dan para pengikutnya. Setelah beberapa bulan lamanya berada di Tondano Kiyai Mojo kemudian berusaha mengolah tanah. Dari tanah yang berawa-rawa menjadi tanah persawahan, tidak begitu saja berhasil. Tumbuhan padi selalu mengering sebelum dipanen. Kiyai Mojo dan para pengikutnya menanam di areal rawa tersebut, tapi selalu mengalami kegagalan. Ternyata tanah tersebut mengandung alkalis yang sangat tinggi. Mereka kemudian mulai dari penggalian tanah rawa kemudian airnya dialirkan ke sungai Tondano. Rawa ini kemudian mengering mulailah mereka menanam kembali. Setelah 40 hari disemai bibit padi dipindakan ke areal persawahan dengan sistem tadah hujan juga sumber air dari pegunungan. Proyek persawahan menghasilkan padi yang melimpah. Rasa kagum Sub suku Tonsea dan Tolour pun muncul, Kiyai Mojo dan para pengikutnya mengundang sub suku Tonsea dan Toulour untuk menikmati hasil panen mereka. Sampai saat ini persawahan tersebut masih eksis yaitu didesa We, Welen dan Tounsaru.

Areal persawahan yang dibangun oleh Kiyai Mojo dan para pengikutnya adalah salah satu interaksi mereka dengan pribumi Minahasa. Sarana di bidang pertanian menjadi sesuatu yang unik dimata para pribumi Minahasa di masa lampau. Ketertarikan mereka dengan kaum pendatang dimulai dengan melihat mata pencaharian Kiyai Mojo dan para pengikutnya. Pribumi Minahasa pun berusaha mencontoh tata tanam dan kelola 
pertanahan. Tanah yang berawa-rawa diubah menjadi areal persawahan. Teknologi pertanian seperti cangkul, parit, bajak, dan lain sebagainya merupakan teknologi canggih bagi pribumi Tondano tertarik dengan teknologi pertanian yang dilakukan oleh para pendatang dari Jawa. Mereka kemudian ikut serta menanamnya untuk dijual, dan terjadilah perubahan dalam pola makan, yaitu makanan pokok diganti menjadi beras dan jagung. Dengan budaya pertanian yang diterima oleh penduduk asli Tondano dan Tonsea merupakan sarana integrasi sosial budaya antara masyarakat Islam Jawa Tondano dengan penduduk asli di samping adanya hubungan kekerabatan melalui perkawinan. (Wawancara Muhammad Tumenggung tanggal 20 September 1999). Bagi masyarakat Jawa budaya pertanian yang diwariskan oleh nenek moyang terdahulu telah menjadikan mereka petani yang ulet, telaten, pekerja profesional, usahawan yang ulet dan tekun. Perkembangan kehidupan masyarakat kampung Jawa menurut Tondano telah menjadi pusat pasar yang penting pada masa kedatangan mereka dari Jawa. Penduduk kampung Jawa bersama dengan penduduk setempat membawa sejumlah hasil bumi ke Tondano, Kema dan Manado untuk dijual (Tumenggung, 1997: 30).

Mata pencaharian utama masyarakat Kampung Jawa Tondano adalah pertanian. Tetangga kampung yang mayoritas beragama Kristen berusaha mencontoh pola pertanian kaum pendatang itu. Masyarakat kampung Jawa Tondano berbagi Ilmu pertanian dengan tetangga kampung mereka yang beragama Kristen, sehingga taraf hidup di antara kedua komunitas ini berimbang. Pola kerjasama mereka begitu erat ketika tanaman padi yang ditanam diusahakan terhindar dari binatang pengganggu seperti babi. Umat Kristen pun sangat toleran dengan tetangga mereka yang beragama Islam dengan menghalau binatang tersebut untuk tidak masuk ke dalam perkampungan Muslim Jawa Tondano.

Sebuah catatan yang berasal dari pengunjung Belanda di tahun 1846 secara jelas menggambarkan keadaan perkembangan perkampungan ini. Mereka menyebutkan bahwa kampung baru ini cukup rapih. Rumah-rumah sangat sederhana berjajar dengan baik, dan mesjid mereka pun dibangun dengan bambu dari atap nipa. Quccker di tahun
1856 menulis bahwa Kampung Jawa ini seperti desadesa di Jawa yang mendapat pengaruh arsitektur Jawa Minahasa. Tidak hanya itu, kebersihan yang menjadi sifat orang-orang Minahasa pun terlihat jelas dalam perkampungan ini (Graafland Minahasa 1991:458).

Keberadaan bangunan tersebut menunjukkan indikasi bahwa telah terjadi asimilasi budaya yang bukan hanya dari segi pemahaman agama ataupun teknologi pertanian, tetapi kaum pendatang juga telah berusaha mencontoh tata letak perumahan. Pemeluk agama Kristen merasa senang dengan kebersihan ini seiring dengan ajaran agama kaum muslimin bahwa kebersihan adalah sebagian dari iman. Ini mengindikasikan bahwa perjumpaan kedua komunitas tersebut tidak hanya karena dorongan ekonomi, tetapi pola hidup yang sama, yaitu sama-sama cinta akan kebersihan.

Secara umum, ada karakteristik ajaran Islam di bidang ilmu dan kebudayaan yang bersikap terbuka, akomodatif tetapi juga selektif, yakni dari satu segi Islam terbuka dan akomodatif untuk menerima berbagai masukan dari luar, tetapi bersamaan dengan itu Islam juga selektif, dengan tidak begitu saja menerima seluruh jenis ilmu dan kebudayaan melainkan ilmu dan kebudayaan yang sejalan dengan Islam. Dalam bidang ilmu teknologi misalnya, Islam menganjurkan kepada pemeluknya untuk bersikap terbuka.

Pemikiran ini pula yang diterapkan oleh kelompok Islam Jawa Tondano di masa-masa awal pengasingannya di Minahasa. Dalam rentang waktu sejak Kiyai Mojo dan pengikutnya disusul pejuangpejuang yang diasingkan dari berbagai daerah telah ikut serta mewarnai kebiasaan masyarakat Minahasa secara turun temurun. Kebudayaan Islam yang dicoba dipadu dengan budaya lokal menghasilkan budaya baru dan menimbulkan akulturasi budaya yang ikut mewarnai berbagai aktifitas kehidupan mereka, yaitu kebudayaan Jawa (pengaruh Jawa) dan kebudayaan Melayu (pengaruh pengasigan kaum padri pengikut Imam Bonjol).

Perlu dicermati kedua tradisi yang bersifat integratif, di mana budaya Islam telah mengalami suatu proses penyatuan dengan budaya lokal. Salah satunya shalawatan Jawa dan shalawatan Melayu sedikitnya telah mampu mendorong minat belajar mengkaji sejarah Rasulullah melalui doa-doa 
maupun lirik-lirik lagu yang mereka lantunkan, disisi lain melalui pembentukan budaya ini nilai seni sebagai naluri manusia yang mencintai keindahan tersalurkand (Graafian, 1969). Pembentukan dua budaya ini tidak terlepas dari aspek peralihan pemeluk agama Kristen, yang kemudian memeluk agama Islam.

Melalui shalawatan-shalawatan yang dilantunkan tidaklah mempersulit usaha para muallaf untuk mempelajari budaya Islam. Kebiasaan menyanyi di dalam gereja saat mereka masih memeluk agama Kristen, tersalurkan dan diganti dengan irama lagu Jawa dan Melayu yang terpaket dalam pengagungan nama-nama Allah dan puji-pujian kepada Rasulullah. Akhirnya, pembentukan kedua kebiasaan itu sangat mempermudah para muallaf untuk memahami dan mempelajari syiar-syiar Islam.

Ada dua tuntutan kerukunan menurut pandangan Jawa. Pertama, ketenangan dan keselarasan sosial, merupakan keadaan normal yang akan terdapat dengan sendirinya selama tidak diganggu, seperti juga permukaan laut dengan sendirinya halus kalau tidak diganggu oleh angin atau oleh badan-badan yang menentang arus. Kedua, prinsip kerukunan merupakan suatu sikap batin atau keadaan jiwa melainkan untuk jaga keselarasan dalam pergaulan (Greetz, 1961: 78). Semua ini tidak terlepas dari pemikiran-pemikiran kaum pendatang yang menyiarkan Islam yang melihat jauh ke depan bagaimana Islam bisa menempatkan posisinya di daerah yang mayoritas pemeluk agama Kristen.

Ada dua kaidah yang paling menentukan pola pergaulan dalam masyarakat Jawa. Kaidah pertama mengatakan bahwa setiap situasi, manusia hendaknya bersikap menghindari konflik. Kaidah kedua mengarahkan sikap manusia dalam berbicara dan membawa diri selalu menunjukan sikap hormat terhadap orang lain, sesuai dengan derajat dan kedudukannya. Kedua kaidah tersebut merupakan kerangka normatif yang menentukan bentuk-bentuk konkrit semua interaksi (Magnis, 1996: 77).

Pertemuan antara individu dari satu masyarakat dengan individu dari masyarakat lainnya, juga memungkinkan terjadi difusi. Ini terjadi juga dengan kebudayaan Islam dengan budaya pribumi Tondano dimana kedua budaya para pendatang diterima dengan tidak sengaja dan tanpa paksaan, maka proses difusi dapat menyebabkan lancarnya proses perubahan. Difusi tersebut telah memperkaya dan menambah unsur-unsur budaya diantara kedua belah pihak. Hal ini dapat terlihat dari serangkaian budaya upacara-upacara tradisi yang masih dipertahankan sebagian besar orang buangan dengan penduduk asli Tondano yang merupakan peninggalan nenek moyang masyarakat berburu atau pra Islam, dan secara garis besar upacara tradisi lokal mampu diserap oleh mereka adalah kebiasaan upacara dalam daur hidup. Untuk memahami dan mencintai Islam, di dalam kehidupan rumah tangga atau keluarga, maka metode yang ditempuh para ulama dahulu adalah memasukkan unsurunsur agama pada siklus kehidupan setiap anggota keluarga itu, baik saat kelahiran, khitanan, perkawinan ataupun kematian (Tumenggung, 1981: 47) Setiap tahapan daur kehidupan itu, para ulama akan mengadakan kegiatan-kegiatan keagamaan. Metode penyebaran Islam melalui ritus keagamaan dalam siklus kehidupan yang dilakukan para ulama pengembang pertama dalam penyebaran Islam inilah yang menjadi titik tolak keberhasilan masuknya Islam di Minahasa.

Di Kampung Jawa Tondano masa peralihan tercermin dalam siklus hidup yakni perkawinan, kelahiran, dan kematian. Hal ini dapat dilihat dari prosesnya yakni: Peningset yaitu suatu perjanjian tidak tertulis mengenai perjodohan, peminangan. Mododareni yaitu upacara pelambang kegadisan (keperawanan) calon pengantin. Sumsoman yaitu silatuhrahmi yang yang dilakukan setelah perkawinan selesai dengan berkunjung kedua mempelai kepada para orang tua yang dituakan untuk menerima nasihat. Tingkeban yaitu upacara mendoakan kehadirat Ilahi atas kelahiran bayi, aqiqah, khitanan, kematian serta Punggahan yaitu suatu kebiasaan yang dilakukan sebelum Ramadhan berkunjung ke makam leluhur. Secara antropologis, kegiatan upacara tradisi lokal sudah sangat lazim, karena itu merupakan simbol-simbol kepercayaan kepada Tuhan Yang Maha Esa. Namun jika ditinjau dari segi syariat Islam hampir tidak ada satupun argumentasi yang jelas memperkuat upacara-upacara ritual di atas. Upacara daur hidup 
seperti acara aqiqah, khitanan, acara pekawinan misalnya sebagian besar merupakan anjuran dan perintah agama, Namun perlu diperhatikan bahwa upacara-upacara ritual tersebut, baik proses dan tujuannya tidak boleh bertentangan dengan tuntunan Islam.

\section{PENUTUP}

Eksistensi Komunitas Jawa Tondano tidak terlepas dari perang Diponegoro yang tercatat dalam sejarah sebagai perang yang menguras habis kas Belanda. Salah satu hal yang dilakukan oleh kompeni Belanda untuk meredam pemberontakan tersebut, yaitu kebijakan pengasingan para pejuang di wilayah Jawa ke daerah- daerah yang tidak dikenal sebelumnya. Kiyai Mojo dan para pengikutnya kemudian diasingkan ke ujung wilayah utara pulau Sulawesi, tepatnya di daerah Tonsea-lama dan Tondano. Mereka akhirnya membangun sebuah perkampungan dan serta mempererat hubungan dengan kaum pribumi dengan menikahi wanitawanita Minahasa. Masyarakat muslim Jawa Tondano.

Melalui budaya pertanian baru yang dikenalkan orang Jawa, dan kemudian diterima oleh penduduk asli Tondano dan Tonsea, para pemberontak itu dapat berintegrasi secara sosial dengan warga pribumi. Bagi masyarakat Jawa, budaya pertanian yang diwariskan oleh nenek moyang terdahulu telah menjadikan mereka petani yang ulet, telaten, serta usahawan yang berhasil. Kampung Muslim Jawa Tondano merupakan pemukiman minoritas di tengah masyarakat Kristen mayoritas. Tetapi, perbedaan keyakinan di antara kedua komunitas ini menjadi sesuatu yang menarik untuk dicontoh oleh dear ah lain. Toleransi diantara dua komunitas ini tetap terjaga.

Oleh karena itu, Pemerintah, dalam hal ini Kementerian Agama sebagai pengayom masyarakat agar lebih dapat memperhatikan kampung Jaton ini sebagai sarana percontohan dalam memupuk toleransi dari kedua komunitas berbeda agama. Bingkai kerukunan umat beragama dapat dicanangkan di daerah ini.

\section{Ucapan Terima Kasih}

Penulis menyampaikan terima kasih kepada Dr.Alie Humaedi, M.Hum yang telah membimbing penulis. Ucapan terima kasih juga penulis sampaikan kepada informan dan seluruh masyarakat Jawa Tondano dan sekitarnya. Tulisan ini tidak akan pernah ada tanpa bantuan para informan baik di lapangan. Kepada redaksi jurnal Al-Qalam yang telah memuat tulisan ini. Semoga tulisan ini dapat bermanfaat bagi pembaca.

\section{DAFTAR PUSTAKA}

Balai Arkeologi Manado Pusat Arkeologi Nasional Departemen P\&K. 1997/1998. Laporan Penelitian Arkeologi KelurahanWalunan Taolimambot Kab. Minahasa SULUT.

Geertz, Clifford. 1961. The Javanese family, A Study of Kindship and Socialization, The Free of Glencoe, London.

Graafland, N. 1869. De Minahasa: Haar Verleden En Haar Tegenwoordige Toestand, Why \& Zonen, Roterdaam.

Gottschalk Louis. 2008. Understanding History.a Primer Of History Method, diterjemahkan oleh Nugroho Notosusanto dengan Judul Mengerti Sejarah. Jakarta: Universitas Indonesia Press.

hhtp:ensiklopedia Jaton.blogspot.com/2009/06/ sawah-sawah di Jaton/htm/ diunduh tanggal 26 Agustus 2014

Kuntowijoyo. 2008. Penjelasan Sejarah (Historical Explanation Jakarta: Tiara Wacana.

Lauer Robert H. tth. Perspektif Tentang Perubahan Sosial, Jakarta: Rieneka Cipta.

Magnis, F.S., 1996, Etika Jawa, Sebuah Analisa Falsafi , tentang Kebijaksanaan Hidup Jawa, Jakarta: Gramedia Pustaka Utama.

Nata. Abudin. 2000 Pendekatan Sosiolog Dalam Studi Islam. Jakarta: Grafmdo Persada.

Shihab Alwi. 1998. Membendung Respon Gerakan Muhammadiyah Terhadap Penetrasi Misi Kristen di Indonesia. Bandung: Mizan.

Tumenggung, Ahmad. 1981. Salawatan Jowo di Kampung Jawa Tondano Suatu Tinjauan Paedogogis. Manado: Tesis Program Pasca Sarjana IKIP Manado.

Tumenggung, Sis. M. 1997. Sejarah Masuknya Islam di Minahasa Jawa Tondano dan Sekitarnya, Manado: Forum Komunikasi Mahasiswa 
Sulut.

Yayasan Kiyai Modjo Provinsi. 1979. Kiyai Modjo Sebagai Pahlawan Perjuangan Kemerdekaan,

Manado.
W, Pranoto Suhartono. 2010. Jawa Bandit-bandit Pedesaan Studi Historis 1825-1942. Jakarta: Aditya Media. 